\title{
The Importance of Smartphone's Usage Among Malaysian Undergraduates
}

\author{
Noor Mayudia Mohd Mothar, Prof. Dr. Musa B. Abu Hassan, \\ Prof. Dr. Md Salleh B. Haji Hassan, Dr. Mohd Nizam Osman \\ Faculty of Modern Language and Communication Universiti Putra Malaysia 43400 UPM Serdang \\ Selangor Darul Ehsan, Malaysia \\ Fakulti Kepimpinan dan Pengurusan Universiti Islam Malaysia Bandar Baru Nilai 71800, Nilai, Negeri \\ Sembilan, Malaysia \\ Faculty of Modern Language and Communication Universiti Putra Malaysia 43400 UPM Serdang \\ Selangor Darul Ehsan, Malaysia \\ Faculty of Modern Language and Communication Universiti Putra Malaysia 43400 UPM Serdang Selangor \\ Darul Ehsan, Malaysia
}

\begin{abstract}
Since its debut, smartphone had been steadily replacing the existence of the conventional mobile phone. The change was well accepted and proven by the smartphones' surging sales throughout these years. Furthermore, smartphone become a necessity to universities students. Apart from allowing them to socially interact with others, it also can entertain as well as provide platform to search for information. Nowadays the smartphone could also be use to channel its owners' personality. This research implies that pattern of smartphone's usage was categories into four typologies that includes Information, Personal Identity, Integration and Social Interaction, and Entertainment. With data from 385 undergraduate students from public and private university in Malaysia, the researcher was able to conclude that the usage for personal identity was important to them. The results were able to clarify the students' interest over their smartphone and confirm its popularity among youngsters.
\end{abstract}

\section{Introduction}

Smartphones are fully featured high-end mobile phones featuring PDA capabilities, so that applications for data-processing and connectivity can be installed on them (Papagiannakis*, Singh, Magnenat-Thalmann, 2007). It's a device that is able to have computing abilities (Norris, 2007), or simply put it is a programmable mobile phone (Raento, Oulasvirta, \& Eagle, 2009). Apart from normal calls and text messaging, smartphone allows the users to play electronic games, listen to radio, watch TV, capture images, store data, Internet access and e-mail. This also includes the mundane usages of smartphones as clocks, calculators and memos and may also be used to subscribe for services and shop, bank, deals in shares or receive the latest football scores. In some of the develop country like Japan and Korea for example, the mobile phones are also used as an automatic credit card or embedded into other devices such as a palm pocket or laptop PC. Putting smartphones' capabilities into perspective, they can be compared to a 1990s desktop PC as to memory, disk (permanent storage) and processing capacity, and network connection (Raento, Oulasvirta, \& Eagle, 2009).

It was revealed that on average, Malaysian youth sent about 20.9 million text messages daily (Institut Penyelidikan Pembangunan Belia Malaysia, 2007). According to Mohd Azam Osman, Abdullah Zawawi Talib, Zainal Aladin Sanusi, TanShieng Yen, and Abdullah Sani Alwi (2011), based on their exploratory study, the most common usage of smartphone is still related to making phone calls and sending text messages. Few other researches on mobile phones (Siew Hock \& Moon Ting Su, 2004; Gurau, 2009; Azwar Aziz, 2009; Nor Shahriza Abdul Karim, Ishaq Oyefolahan Oyebisi, \& Murni Mahmus, 2010; \& Mohd Azam Osman et al., 2011) also reported similar findings. This type of usages could be typically categorized for Integration and Social Interaction as it involved ability to connect with others and fulfilling out social roles. Thus a sophisticated device like smartphone with its many capabilities and functions seemed wasted if it is only recognized for its mundane use such as calling and texting.

It was proven earlier that the rise of smartphone is inevitable, unfortunately most of the study in Malaysia (Institut Penyelidikan Pembangunan Belia Malaysia, 2007; Nor Shahriza Abdul Karim et al., 2010; \& Mohd Azam Osman et al., 2011) only focused on the main usage of the smartphone that centred on Integration and Social Interaction. Therefore there is a gap in knowledge as researches on the importance of its usage of Information, Entertainment, and Personal Identity for smartphone is currently disregarded. In this research, the researcher focus on the smartphone's importance of usage that includes its use for integration and social interaction, entertainment, information, and personal identity. To the best of the researcher's knowledge there 
are no results in the literature that focus on McQuail (as cited in Miller, 2005), typology of usage, which includes Integration and Social Interaction, Information, Entertainment, and Personal Identity with regard to smartphone. Therefore the aim of the present work is to investigate the importance of usage of smartphone that revolves around McQuail's typology of usage. The result implies that smartphone was most suitable for indicating their personal identity as it helped to represent or reflect their extended self to the others.

\section{Literature Review}

In the telecommunication industry, Malaysian mobile phone sales continue to rise and the sales accounted about $66 \%$ of consumers electronic spending in the year 2010 and by the year 2015 it was estimated to reach 40 million users (Business Monitor International, 2011). It was reported that $85 \%$ of Malaysian own mobile phones (Mohd Azam Osman et al., 2011). Regardless of that, in 2010, the number of smartphones sold worldwide jumped 49 percent from a year earlier to 54.3 million units (Voight, 2010). It was reported that smartphones are the only segment of the global cellphone business expected to expand in 2012 (Lam, 2012). According to Nielson Wire (2012) overall smartphone penetration stood around $48 \%$ (in the U.S) by the end of Jan 2012. Furthermore based on the Nielsen 2012 Smartphone Insights study, Malaysia's smartphone penetration rate is at $27 \%$ in 1Q of 2012 (as cited in Ee Laine Wong, 2012 May 8). Malaysia Telecommunication and Multimedia Commission forecasted that smartphone would account for $23 \%$ of all new mobile phones sold annually by the year 2013 (as cited in Safiek Moklis \& Azizul Yadi Yaakop, 2012).

It seemed that the high price of the smartphone did not interfere with consumer's decision to adopt the smartphone. In fact, there were various consumers' researches that predicted the increased in smartphone's consumption in the market (Zahra Seyed Ghorban, 2012). For instance, it was also predicted that the number of mobile phone users in Malaysia, would reach 40 million by 2015 as mobile subscribers passes 124\% (Business Monitor International, 2011). It was also found that majority of smartphone users are teenagers and young adults (Mohd Azam Osman, Abdullah Zawawi Talib, Zainal Aladin Sanusi, TanShieng Yen, \& Abdullah Sani Alwi, 2011). Furthermore according to Forrester (2012) by 2016, it was said that there would be one billion smartphone consume by consumer.

One factor that may contribute towards its success in Malaysia is the affordable plan that the telecommunication companies offers to its customers (Mohd Azam Osman et al., 2011; Johari Hassan \& Raja Shahrina Raja Abdul Rashid, 2012). Most of telecommunication companies in Malaysia offers contractual plan to its customers that would include call, SMS, and Internet data rates (Zahra Seyed Ghorban, 2012). Currently there are three main telecommunication companies or telcos that offers plans for smartphone owners (Mohd Azam Osman et al., 2011). The telcos are Celcom, Maxis, and Digi. These telcos are always competing to dominate the market. Although these telecommunication companies offer great deal of Internet connection to its customers it was revealed that Malaysian preferred Wi-fi connection compare to 3G connections (Mohd Azam Osman et al., 2011).

In term of mobile phone business, mobile music consumption will increased mobile phone traffic and pour revenue into the pockets of phone developers, record companies and mobile service provider (Wang, 2005). Other than that, it was reported that in China, mobile gaming has emerged as a growing industry as companies seek to access the 334.8 million Chinese mobile telephone users (Soderberg, Bjorkstrom, Liu, Dean, Wei, \& Meiqin, 2005), and most of them are youth. The mobile phone industry expects the introduction of new designs and applications such as mobile Internet, camera phone, video phones, and built in $\mathrm{mp} 3$ players and radio to be determine by the preference of young people (Thulin and Vilhelmson, 2007) and most students postpone their purchase of fashionable mobile phone until they went to university (Yoon, 2006). In Malaysia Mohd Azam Osman et al. (2011) in their research revealed that Nokia, Sony Ericson, and iPhone are the most popular brand in Malaysia.

In 2007, Watkins (2009) and a team of researchers began to study youth's media behaviours. Around 560 surveys were collected and after 107 interviews later they concluded that 96 percent of the youth they surveyed own a mobile phone. According to him, as they began to analyze the data from the surveys they collected and transcribed the stories youth shared with them about their technology rich lives, it was vividly clear that digital is more than the tools and technology they use, it is a way of life. The Pew Internet \& American Life Project (2002) study also provided evidence that this group spends more than average on all sorts of technology goods and services.

According to Cho Han (2000), a survey was conducted in Korea to determine the position of mobile phone in the lives of students. In this survey, the students were calling the second-generation mobile phone as 'dumb'. A 'dumb' mobile phone is associated with the respondent's position as a student. Youth most likely to consider mobile phone with attractive physical look as well as other qualities of the gadget that are perceived as means towards accentuating their social status (Nor Shahriza Abdul Karim et al., 2010). Apart from that, Nor Shahriza Abdul Karim et al. (2010) also believed that the users also used mobile phone for the purpose of socialization and entertainment. The superiority of the smartphone design and its capabilities no doubt will 
provide its users with best experience it could provide. De Gournay and Smoreda (2003), Ling (1998) and McVeigh, (2003) all agreed that among various forms of new technology, the mobile phone in particular has been perceived as a significant symptom and facilitator of individualizing youth culture, since it is by definition individually owned unlike some other technologies and is believed to construct space exclusively for young people. According to Yoon (2003b), most of the youth in Seoul Korea would agree that they used mobile phone to contact friends and family. Youth saw the mobile phone as a desire to keep in touch with friends, but their parent saw this as an opportunity to improve parent's accessibility to their children (Oksman \& Turtiainen, 2004).

In Malaysia, universities students saw mobile phone as a necessity as it alters the learning method at the higher learning institutions (Syed Yahya Kamal, Syed Ardi \& Tasir, Zaidatun, 2008). Students used smartphone for instance to share notes between classmates, record lectures, as well as take pictures of the assignments for future reference, share exam results via facebook, or even using Bluetooth to share information. Smartphones is one type of media that can facilitate opportunities to develop extremely strong, persistent, and real-time ties to their peers while also interacting with a wide range of cultural content such as pictures, music, and video (Watkins, 2009). Also the utilization of the smartphone SMS features and Internet applications has resulted in the expansion of people's social networks and connections with instant personal updates from people in their social networks (LaRue, Mitchell, Terhorst, \& Hassan A. Karimi, 2010). According to Walsh and White, many mobile phone users have reported that they personalized the features (eg: ringtones, displays) on their phone to reflect their personal likings (as cited in Burger, Riemer, Grafeneder, Woisetschlager, Vidovic, \& Hergovich, 2010).

When purchasing a smartphone, there are many things to consider such as the communication, interface, productivity, multimedia, choice, and apps (Battle Of The Smartphone, 2011 February 5). In addition according to Mohd Azam Osman et al. (2011), the design of the smartphone was also reported as most common specification that the user considers when a buying smartphone. Safiek Moklis and Azizul Yadi Yaakop (2012) claimed that three most important factors influence customers' choice of mobile phones are innovative features, recommendation, and price.

Youth in Malaysia was reported to prefer camera feature, and SMS because of the cost effectiveness (Nor Shahriza Abdul Karim et al., 2010). Malaysian preferred SMS because SMS is a cheap form of communication and is quite affordable (Gabarre \& Gabarre, 2009). Around the world SMS had already became a multibillion-dollar industry (Parry, 2011). Nor Shahriza Abdul Karim et al. (2010) discovered that users used features like SMS, voice calls, music, alarm clock, address book, calendar, and camera for socialization, and entertainment purposes. Similarly, Mohd Azam Osman et al. (2011), also found that typical smartphone usage apart from phone calls, and SMS, would feature slightly advance usage such as MMS, multimedia playing, and operating common applications. These features are what made smartphone a smart device. These functions require more technically advanced used of the mobile phone and apparently this technological sophistication tends to correlate with younger users (Axelsson, 2010).

According to Sabri and Masud, university students in Malaysia felt that the amount of money that they received was not even sufficient to cover their financial needs, let alone it was adequate to spend for expensive mobile phones (as cited in Safiek Moklis \& Azizul Yadi Yaakop, 2012). Nonetheless Nor Shahriza Abdul Karim et al. (2010) revealed that their research indicated that the majority of students prefer expensive phone and love to explore the latest model of their preferred mobile phone brand. Although most of the students complained of not having enough money a research showed that students tend to attach greater importance on 'price' when purchasing mobile phone (Safiek Moklis \& Azizul Yadi Yaakop, 2012).

The rise of smartphone is inevitable, unfortunately most of the study in Malaysia (Institut Penyelidikan Pembangunan Belia Malaysia, 2007; Nor Shahriza Abdul Karim et al., 2010; \& Mohd Azam Osman et al., 2011) only focused on the main usage of the smartphone that centred on Integration and Social Interaction. Other researches would focus on the smartphone's sales, penetration rate, smartphone's adoption and position, or its users' preference. Therefore there is a gap in knowledge as researches on the smartphone's usage for Information, Entertainment, and Personal Identity is currently disregarded.

Furthermore in previous research by Oksman \& Turtiainen (2004), Caronia \& Caron (2004), and Yoon (2003b), all discussed the mobile phone usage among youth, but in their research they were only looking at singular usage of the mobile phone separately. However in this research the researcher identified the most important usage based on McQuail's typology of usage. Thus this research helped to fill the gap in the knowledge and assist policy makers, technology developers, as well as service providers in better understanding of the situation and for planning development for youth in the area of the new technology.

\section{Research Methodology}

The research was conducted on Malaysian youth age between 18 to 27 years that was enrolling in the bachelor degree at the government as well as private universities. The respondents mostly included university 
students where their current source of income would be from their parent, student loans, scholarship, or even those who have part time job. The rationale behind this was that they would have more funds than the high school students, and better means to afford the smartphone. There are a total of 20 Government's Institute of Higher Learning and 23 Private's Institute of Higher Learning with university status in Malaysia. Based on that the researcher randomly selected three from each list. The universities that were selected to represent the Government's Institute of Higher Learning were Universiti Islam Antarabangsa Malaysia (UIAM), Universiti Putra Malaysia (UPM), and Universiti Malaya (UM), while Universiti Tun Abdul Razak (UNITAR), Universiti Industri Selangor (UNISEL), and Universiti Multimedia Malaysia (MMU) to represent the Private's Institute of Higher Learning.

This research concentrated on the importance of smartphone's usages among the undergraduates. The researcher only selected those students that are studying around Selangor region and were in the process of completing their bachelor degree. The rationale from selecting undergraduate students as respondents was because of their scale of population and common degree that the respective universities offer. According to statistics from Malaysian Ministry of Higher Education, the populations of students who enrolled for bachelor degree in various fields in 2010 were 274,690 for Government's Institute of Higher Learning and 220,299 for Private's Institute of Higher Learning respectively. The sample size was decided based on Krejcie \& Morgan's (1970) table for determining sample size. The samples were collected from the faculty of Arts, Social Science, Information Technology, and Economic of the respective universities. This was mostly because all of the six universities offered at least one or more courses on these fields of studies. This was to ensure common ground factor among these universities.

There were 385 respondents involved in this research and purposive sampling was used in the sample selections. This means that those qualified to participate in this research need to own a smartphone. Prior to conducting the actual data collection, the researcher had conducted pilot test involving nearly 50 respondents. The result for reliability analysis was relatively high with most items scores Alpha Cronbach above .07. The researcher prepared structured questionnaire to address the research objective. The instrument for this research used five-point likert-type scale. The likert-type scale was used to address the level of importance of the smartphone to the users based on the McQuail's typology of usage.

Proceeding to the analysis, the researcher conducted normality test to confirm for normal distribution. As most of the data did not have normal distribution, the researcher used the SQRT, LOG, and Inverse transformation to normalize the distribution. Based on the research objective, the statistical procedure that the researcher used includes descriptive statistics.

\section{Results and Discussion}

There were 385 respondents participated in this research and more than half of the respondents are female. Furthermore more than half of the respondents are of Malay ethnic (70.9\%), followed by the Chinese $(19.5 \%)$ and the rest are Indians and other ethnics. The age ranged from 18 to 27 years old whereby more than half of the respondents were between 21 to 23 years old (58.4\%). The respondents comprised of undergraduate students that enrolled at the public and private universities in Selangor state and most of the respondents were first year students followed by second year students, and the rest of the respondents consist of the third and final year students.

Nearly all of the respondents had between one to two mobile phones. It could be said that having more than one mobile phone was the practice for respondents. It could be that one of the two of mobile phone could be the $2 \mathrm{G}$ mobile phone that they have before they start owning the smartphone. Safiek Moklis and Azizul Yadi Yaakop (2012) revealed that some of the key trends and developments in Malaysian mobile telecommunication industry were related to the growing popularity of the smartphone among Malaysian consumers. Thus the Malaysian consumers may have decided to buy the smartphone to add to their collection of mobile phone, even if they still have a $2 \mathrm{G}$ mobile phone that is still functioning. Young people's ownership of mobile phone signifies that they had reached the age where they can be considered relatively independent in the family and in public (Yoon, 2006).

In Malaysia there are three main telecommunication network that provided service for mobile phone that consist of Celcom, Maxis, Digi. On the other hand, U Mobile is a telecommunication company that started to get recognized in the Malaysian telecommunication market. U Mobile claimed that they have $98 \%$ coverage in populated area, however their $3 \mathrm{G}$ coverage were only available in Ipoh, Klang Valley, Seremban, and Johor (U Mobile, n.d). Since this research was done in Selangor therefore, four respondents were identified to subscribe to U Mobile. The most popular service provider for this research was Maxis. This finding is similar with Mohd Azam Osaman et al. (2011), in their research it was also reported that the most popular service provider was Maxis. This was probably because currently Maxis continued to lead the market with a total of 13.8 million subscriptions, including revenue generating subscription base of 12.6 million (New Straits Times, 2012 June 1). Some of the respondents did not subscribed for the data plan with these main networks, decided to wirelessly 
connects to the Internet via other Internet providers such as Telekom Malaysia (TM), JARING, and P1Wimax. These services usually are available at home or public places such as restaurants that offers free Wi-fi connection. More than half of the respondents had been using their smartphone for at least a year and subscribed to prepaid plan. This was similar to Handphone User Survey that was conducted in 2007, in the survey it was also discovered that more people subscribed to prepaid plan than the postpaid plan (Suruhanjaya Komunikasi dan Multimedia Malaysia, 2008). This was because students are usually reluctant to subscribe to a postpaid plan because of the commitment fee that would have to endure for a period of time. Prepaid account on the other hand let them plan their spending based on their available budget and need.

For most of the respondents, their decision on choosing a smartphone rest on the smartphone's functions (78.8\%). It was true smartphone had many ability especially when the device was Internet enable. Thus the usability (56.1\%) also became the second decisive factor in decision on choosing a smartphone. Other factors included budget (31.9\%), other's influence (21\%), following trend $(20.8 \%)$, fashion statement $(17.9 \%)$, and others (4\%). In the earlier research on mobile phone it was discovered that fashion play a significant role in mobile phone's adoption (Katz, and Sugiyama, 2006) however in this research it seemed that the respondents were more interested in the smartphone's function rather than fashion statement. Among others the respondents also stated that they have no choice with the decision on choosing the smartphone as some of them received their smartphone as a presents from others. There were also cases where they received 'hand down' smartphone from others. Some of others chose their smartphone based on others' influence, fun, design, inexpensive, and also because it has longer battery life.

More than half (59\%) of the respondents were responsible for their own phone bills. This most probably was because the respondents were already considered an adult and many of them received study loans, scholarship, or even allowances from the respective sponsors such as family members or the government. It was also true that many of them subscribed to prepaid plan (78.7\%) as they could manage their monthly phone bill according to their budget.

The most popular features on the smartphone that the respondents' used were mostly to send and receive text messages $(97.9 \%)$, take pictures $(97.1 \%)$, play music $(96.1 \%)$, setting the alarm $(95.8 \%)$, referring to the calendar $(94.5 \%)$, recording videos $(92.5 \%)$, play games $(91.9 \%)$, and exchanging pictures via Bluetooth $(91.7 \%)$. It seemed that in this research most of the respondents used their smartphone for sending and receiving text messages. Similar with previous research (Thulin, \& Vilhelmson, 2007), text messages had became important means that helped to maintain the respondents' interaction with others. Furthermore similar with this research, other research also reported that the most popular features were taking pictures and playing music (Thulin, \& Vilhelmson, 2007; Lenhart, Ling, Campbell, \& Purcell, 2010; Licoppe, 2011).

These were also the standard features that any average mobile phone had, and the transition from using the normal or the second generation mobile to smartphone was easily done because now the smartphone had the ability to do much more such as connecting to the Internet and logging on to the Social Networking Site. According to Leung (2009) overall that Internet users spend 16-30 minutes per day on the Internet or the user generated content activities that included personal web pages, blogs, forums, posting video on YouTube, and contributing information on Wikipedia. The appealing factors of the Social Network Site such as Facebook for example encouraged specific behaviours such as 'Friending' a family member and responding to Friends' requests on the site. According to Vitak, Ellison, and Steinfield, (2011) this behaviour predicted perceptions of three types of social support: attachment - a sense of security and place; reliable alliance - the belief that there will always be people there to help; and guidance - the provision of support and advice during stressful times. Most probably these support encouraged most of the youth to continuously log on to the social network sites. As mention earlier connecting to social sites network or any other sites is easy via the smartphone as the smartphone features and design compliment this new type of technology.

Apart from that the respondents that used smartphone from the same brand could also utilized the messaging feature that was available if there are online. For instance Blackberry users can 'BBM' each other for free with no extra charge apply. Furthermore the design of the smartphone gave advantage for game developers to develop better games as the respondents could experience bigger screen, and better resolution with smartphone comparing to the average mobile phone. Quan-Haase and Young (2010) have identified two important trends of the used of the social media that includes the user's tendency to employ a range of tools for communication and also tend to embrace new tools and adopt them as part of their communication repertoire.

The Importance Of Smartphone Usage Among Undergraduates Based On The Usage For Entertainment, Information, To Reflect Personal Identity, And For Integration And Social Interaction.

According to Blumler (1979), the users own experience and perspectives changed the role of audience from passive receiver to active users. In this research, the researcher studied four typologies of usage that includes the usage for integration and social interaction, information, entertainment, and to reflect personal identity. As mentioned earlier these typologies were quite important in determining the usages of the smartphone among Malaysian undergraduates. The focused of this particular objective was to identify the most 
important typologies that were acknowledged by the respondents. Thus the researcher studied the mean of the gratification sought of each typologies and the highest mean represent the respondents' choice of preference.

Based on the Table 1, Personal Identity had the highest mean among the typologies (Mean=3.47) and therefore based on the result, Personal Identity is deemed to be the most important typology to the respondents. The result is in consistent with Harris Interactive (2007) findings that described the users' personal style (which is also equivalent to personal identity) motivate users in using smartphone. The smartphone could be seen as the extension of oneself (McLuhan, 2006) as smartphone becomes a personalize medium to its users. The findings was also consistent with Oksman and Turtiainen (2004) and Ling (as cited in Thulin \& Vihelmson, 2007) believed that mobile communication has become important reasons for young people in defining their personal space and that they used communications channels as means of self-expression in reflecting the identity of young people. Moreover Osman, Zawawi, Sanusi, Yen, and Alwi (2011), suggested that generally in Malaysia, smartphone would be an indicator of status, prestige, and lifestyle for younger adult with purchasing power. Nor Shahriza Abdul Karim et al. (2010) also supported the idea that younger group age has the tendency to be more attracted to adopt or purchase mobile phone due to its physical attributes and the status it reflects. It is important to note that the smartphone is important in reflecting one's identity and young people may be overlooking the expensive price of the these devices in order to be satisfied by the its representation.

Table 1: Rank Of The Most Important Typologies. $(\mathrm{n}=385)$

\begin{tabular}{lrrrrr} 
McQuail's Typology of Usage & \multicolumn{1}{l}{ Min } & \multicolumn{1}{c}{ Max } & Mean & Std. Dev. \\
& & 1.13 & 4.46 & 3.4683 & .82767 \\
Personal Identity & & 1.16 & 4.33 & 3.3968 & .68449 \\
Information & & 1.00 & 3.63 & 2.8728 & .50720 \\
Entertainment & & 1.27 & 3.11 & 2.6096 & .32801
\end{tabular}

Note: $1=$ not important at all, $2=$ less important, $3=$ important, $4=$ more important, $5=$ most important, Standard Deviation=Std. Dev.

The reasons Personal Identity was ranked as most important was probably because the respondents may be using other media such as computer, ipod, magazines, newspaper, television, and etc. when searching for Information, Entertainment, and Integration and Social Interaction. Young people today have access to more than one media and they learn how to multitask. Even though smartphone may be the medium that respondents can rely on its mobility but it is not suitable for heavy-duty work. For instance when working on assignment, the smartphone's screen is too small comparing to a PC or a laptop and PC or laptop allowed them to work comfortably. Furthermore PC or laptop allows them to multitask as they could search for information, play games and listening to music, also log on to social network site all at the same time. They can also search for information or entertainment by using other media such as television, radio, ipod, and the print media. As undergraduates are part of the younger generation that recognized the importance of social status, the smartphone was most suitable for indicating their personal identity that confirms their social status. As adult uses materials such as money, house, or car to display their social status, the concept is similar with the younger people. It was discovered in another research that young people choose things like shoes, watch or jewellery, cellphone, and clothing as their indicator for social status (Harris Interactive, 2007).

Belk (as cited in Ahuvia, 2005) sees that a consumer possessed a core self that is expanded to includes items that were then becomes part of the extended self. The smartphone was used mostly because it indicated their personal style and their personal style should socially place them among others. The smartphone then became the identity construct device (Caronia, 2005; Schwartz, Mullis, Waterman, \& Dunham, 2000) that reflects themselves to others. Thus in this case the respondents have chosen Personal Identity over other typologies.

\section{Conclusion}

The main goal of this research was to identify the importance of smartphone's usage based on McQuail's typology of usage. Based on the result, the data suggest that most of the smartphone users agreed that the use for Personal Identity was important to them. The result signified that when it came to smartphone, Malaysian undergraduates value their smartphone as it identifies their personality and it could act as an extension of oneself. Therefore, the finding would be able to explain the rising of smartphone consumption and its popularity among young people. It seems that regardless of whether they already own a conventional mobile phone, smartphone is a must have item that would answer to several of their needs in term of its practicality as well as what it could symbolize. Although this research clearly points out the most important usage of the smartphone, unfortunately the researcher became conscious of the fact that the result lacks in intimate knowledge, as the researcher could not understand the respondents' insights, feelings, and human perspectives. 
Future research therefore should be conducted qualitatively to provide the general causal explanations as well richer evidence. In addition, the researcher would also suggest widening the scope of the respondents to include the general public. Currently the result was relevant to describe the undergraduate of the local universities unfortunately the researcher would not be able to generalize the findings to describe the whole population. Thus by expanding the research to include the general public, the findings may be more relevant for much wider audience.

\section{References}

[1] Azwar Aziz (2009). Implementing Strategi Marketing Mix Dalam Persaingan Telepon Selular. Komunikasi Massa, 5(2), 153-170.

[2] Business Monitor International (2011). Malaysia Telecommunications Report, (2011), London: Business Monitor International.

[3] Cho Han, H. (2000). Kids Looking For School, Society Looking For Kids. Seoul: Ttohanau־imunhwa.

[4] De Gournay, C., \& Smoreda, L. (2003). Communication Technology and Sociability:Between Local Ties and "Global Ghetto"?, In J.E. Katz (ed.) Machines That Become Us: The Social Context of Personal Communication Technology (pp. 57-70). New Brunswick, NJ: Transaction Publishers.

[5] Ee Laine Wong (2012, May 8). More Malaysians Using Smartphones. Marketing Interactive.com. Retrieved from http://www.marketing-interactive.com/news/32749

[6] Forrester (2012). Forrester Research Mobile Adoption Forecast, 2012-2017 In 'One Billion Smartphones By 2016, Says Forrester'. Retrieved on February 20, 2012, from http://www.zdnet.com/blog/bt1/one-billion-smartphones-by-2016-says-forrester/69279.

[7] Gurau, C. (2009). The Mobile Services Market: An Exploratory Analysis Of Mobile Phone Usage By French Consumers. In Unhelkar, B. (Ed.) Handbook Of Research In Mobile Business: Technical, Methodological, \& Social Perspectives. (pp. 260-268). Hershey: Information Science Reference.

[8] Institut Penyelidikan Pembangunan Belia Malaysia (2007). Fakta Belia. Putrajaya: Perpustakaan Negara Malaysia.

[9] Johari Hassan, \& Raja Shahrina Raja Abdul Rashid (2012). Ketagihan Penggunaan Internet Di Kalangan Remaja Sekolah Tingkatan Empat Di Bandaraya Johor Bahru. Journal Of Technical, Vocational \& Engineering Education, 6, 23-43.

[10] Lam, W. (2012). Samsung Overtakes Nokia For Cellphone Lead. Retrieved on April 26, 2012, from: http://www.isuppli.com/Mobileand-Wireless-Communications/ News/Pages/ Samsung-Overtakes-Nokia-for-Cellphone-Lead.aspx

[11] Ling, R. (1998). “One Can Talk About Common Manners!": The Use Of Mobile

[12] Telephones In Appropriate Situations. Telektronikk, 98(2), 65-76. doi: 10.1111/j.1083-6101.2010.01520.x

[13] Nielson Wire (2012). Survey: New U.S. Smartphone Growth By Age And Income. Article published on February $20,2012$. Retrieved from http://blog.nielsen.com/ nielsenwire/?p=30950

[14] Norris, T. D. (2007). Sales Communications In A Mobile World: Using The Latest Technology And Retaining The Personal Touch. Business Communication Quarterly, 70(4), 492-498. doi: 10.1177/10805699070700040205

[15] Nor Shahriza Abdul Karim, Ishaq Oyefolahan Oyebisi, \& Murni Mahmud (2010). Mobile Phone Appropriation Of Students And Staff At An Institution Of Higher Learning. Campus Wide Information System, 27(4), 263-276. doi: http://dx.doi.org/10.1108/10650741011073806

[16] McVeigh, B.J. (2003). Individualization, Individuality, Interiority, and the Internet: Japanese University Students and E-Mail. In N. Gottlieb and M. McLelland (Eds.) Japanese Cybercultures (pp.19-33). London: Routledge.

[17] Miller K. (2005). Communication Theories: Perspectives, Processes and Contexts. Texas: McGraw Hill.

[18] Mohd Azam Osman, Abdullah Zawawi Talib, Zainal Aladin Sanusi, Tan Shieng Yen, \& Abdullah Sani Alwi (2011). An Exploratory Study On The Trend Of Smartphone Usage In A Developing Country. In E. Ariwa, \& E. El-Qawasmeh (Eds.), Digital Enterprise and Information Systems (pp. 387-396). London: Springer Berlin Heidelberg.

[19] Oksman, V., \& Turtiainen, J. (2004). Mobile Communication As A Social Stage Meanings Of Mobile Communication In Everyday Life Among Teenagers In Finland. Journal of New Media and Society, 6(3), 319-339. doi: 10.1177/1461444804042518

[20] Papagiannakis, G., Singh, G., \& Magnenat-Thalmann, N. (2007). A Survey Of Mobile And Wireless Technologies For Augmented Reality Systems. Comp. Anim. Virtual Worlds 2008, 19(1), 3-22. doi: 10.1002/cav.221

[21] Pew Internet \& American Life Project (2002). The Internet Goes to College: How

[22] Students Are Living in the Future with Today's Technology. Retrieved October 7, 2008, from http://www.pewinternet.org/reports/index.asp.

[23] Raento, M., Oulasvirta, A., \& Eagle, N. (2009). Smartphones: An Emerging Tool For Social Scientists. Journal of Sociological Methods Research. 37(2) 426-454. doi: 10.1177/0049124108330005

[24] Safiek Moklis, \& Azizul Yadi Yaakop (2012). Consumer Choice Criteria In Mobile Phone Selection: An Investigation Of Malaysian Universities Students. International Review of Social Sciences \& Humanities, 2(2), 203-212.

[25] Siew Hock Ow, \& Moon Ting Su (2004). A Survey On The Opinions Of The Malaysian Pertaining To Mobile Phone Features: Price, Feature, Function, Technology And Accessory. CMU Journal, 3(3), 289-308.

[26] Soderberg, B., Bjorkstrom, J., Liu, B., Dean, T., Wei, X., \& Meiqin, F. (2005). The ICT Landscape in the PRC; Market Trends and Investment Opportunities. Report produced for the International Finance Corporation by Spintrack AB and BDA China Ltd. Stockholm: International Finance Corporation.

[27] Thulin, E., \& Vilhelmson, B. (2007). Mobiles Everywhere Youth, The Mobile Phone, And Changes In Everyday Practice. Young Nordic Journal of Youth Research, 15(3), 235-253. doi: 10.1177/110330880701500302

[28] Voight, J. (2010). What The Duel Between Google And Apple's Operating Systems Means For Brands. MediaWeek. 6/28/2010. 20(26) $10-12$

[29] Wang, J. (2005). Youth Culture, Music, And Cell Phone Branding In China. Journal of Global Media and Communication, 1(2), 85 107. doi: $10.1177 / 1742766505054633$

[30] Watkins, S. C. (2009). The Young And The Digital: What The Migration To Social-Network Sites, Games, And Anytime, Anywhere Media Means For Our Future. Massachusetts: Beacon Press.

[31] Yoon, K. (2003b). Consuming Youth In South Korea. Paper presented at the Third International Convention of Asian Scholars, National University of Singapore, 19-22 August.

[32] Yoon, K. (2006). Local Sociality In Young People's Mobile Communication: A Korean Case Study. Childhood, 13(2), 155-174. doi: $10.1177 / 0907568206062924$

[33] Zahra Seyed Ghorban (2012). Brand Attitude, Its Antecedents And Consequences: Investigation Into Smartphone Brands In Malaysia. Journal Of Business Management, 2(3), 31-35. 